\title{
GPPS-BJ-2019-0100
}

\section{EFFECT OF CASING TREATMENT ON THE TYPE OF INSTABILITY INCEPTION IN A HIGH-SPEED AXIAL COMPRESSOR}

\author{
Wenqian Wu \\ School of Energy and Power Engineering, \\ Beihang University, Beijing, China \\ wuwenqian@buaa.edu.cn
}

\author{
Tianyu Pan \\ School of Energy and Power Engineering, \\ Beihang University, Beijing, China \\ pantianyu@buaa.edu.cn
}

\author{
Qiushi Li \\ School of Energy and Power Engineering, \\ Beihang University, Beijing, China \\ liqs@buaa.edu.cn
}

\begin{abstract}
Flow instability phenomena limit the operating range of compressors, so the study of instability inceptions has received a lot of attention. Casing treatment is a commonly used technique to extend the operating range. In order to study the effect of casing treatment on the instability inception and its evolution, experimental investigations are carried out on a transonic axial flow compressor operating at a low rotor speed. By comparing the dynamic instability signals with and without casing treatment, it can be found that the existence of casing treatment can alter the type of instability inception and restrain its development. Based on the discussion of the simulation results, the radial redistribution of blade loading caused by the casing treatment is considered to be the main reason for the change of instability inception.
\end{abstract}

\section{INTRODUCTION}

Flow instability, such as surge and rotating stall, limits the stable operating margin of a compressor. When a compressor is throttled to the boundary of flow instability, an unstable phenomenon in form of rotating stall or surge will occur and may cause serious events in engineering practices. Moore and Greizter [1] and Hynes [2] pointed out that there might be some disturbances occurring prior to the final flow instability, which later was identified as stall inceptions. Epstein [3] proposed that it is meaningful to study stall inception to achieve the active/passive control aiming to inhibit the occurrence of stall.

Consequently, a lot of studies have been followed on various types of instability inceptions. Two of them are well accepted by the community: one is the "modal" inception and the other is the "spike" inception. Modal wave $[1,4]$ is a small-amplitude disturbance with a wavelength of the order of the annulus circumference. The initial modal disturbances rotate at about $50 \%$ of the rotor speed and may evolve into a fully developed stall cell in tens or hundreds of rotor revolutions. Spike $[5,6]$ is a disturbance located at rotor tip, having a length scale of about several blade pitches. This disturbance is found to propagate at about $70 \%$ or more of the rotor speed. Once spike is detected, it will rapidly develop into a large stall cell within ten rotor revolutions, much faster than the growth of modal type inception. At the same time, other types of pre-stall disturbances have also been reported, such as rotating instabilities [7] which occur near the tip of rotor blades with large clearances, and the stall cells rotating at a very low speed in the rotor hub region [8]. In our previous studies $[9,10]$, localized surge-like disturbances in the hub region were also observed prior to stall, and were called as "partial surge" according to the key features, which is an axisymmetric low-frequency disturbance, and will result in stall cells by inducing oscillation of mass flow through the tip region.

With the progress in the understanding of stall precursors, different types of flow control methods have been proposed and studied. Among them, casing treatment is the most common one. For the researches about the casing treatment, most of them focus on the overall performance to improve the stall margin and reduce the efficiency penalty by testing different forms of casing treatment, which includes circumferential groove [11-13], skewed slot with different shapes [11-15], self-recirculating casing treatment [16], SPS 
casing treatment [17]. On the other hand, some researches pay attention to the influence of casing treatment on detailed flow field, trying to explain how casing treatment delays the stall [18-20]. These studies indicate that the casing treatment can delay the occurrence of instability inception by inducing a recirculating path to reduce flow blockage at rotor tip.

For the compressor we studied, the instability inception is partial surge at high rotor speeds (above $78 \%$ of the design rotor speed), while at $65 \%$ of the design rotor speed, spike type inception will occur. Our previous study [21] has demonstrated that at the high rotor speed, the existence of casing treatment cannot delay the occurrence of partial surgetype inception, but will improve the stall margin greatly by preventing the inception's evolution. For this compressor at $65 \%$ design speed, however, the questions that if the casing treatment will work and what will happen to the instability inception are still unknown. Therefore, the experimental studies are carried out at $65 \%$ design rotor speed to detect the stall processes with and without casing treatment, with the focus on the type of stall inception and its evolution.

This paper is organized as follow. First, the research subjects and experimental method are briefly introduced in Sec. 2. Then in Sec. 3, the experimental results of the two cases (with and without casing treatment) are compared regarding the compressor performance, the instability disturbance and its evolution. Finally, the effect of casing treatment is discussed in Sec.4, followed by the concluding remarks in the last section.

\section{RESEARCH SUBJECTS AND METHODOLOGY}

\section{Research Subjects}

The schematic diagram of the testing facility is shown in Figure 1. The compressor is driven by a power turbine through a transmission system, and its rotation speed can be adjusted continuously up to $24000 \mathrm{rpm}$. The throttle valve is located at the outlet of the compressor. By adjusting the outlet throttle valve, the flow rate of the compressor can be controlled, thus moving to different working points.

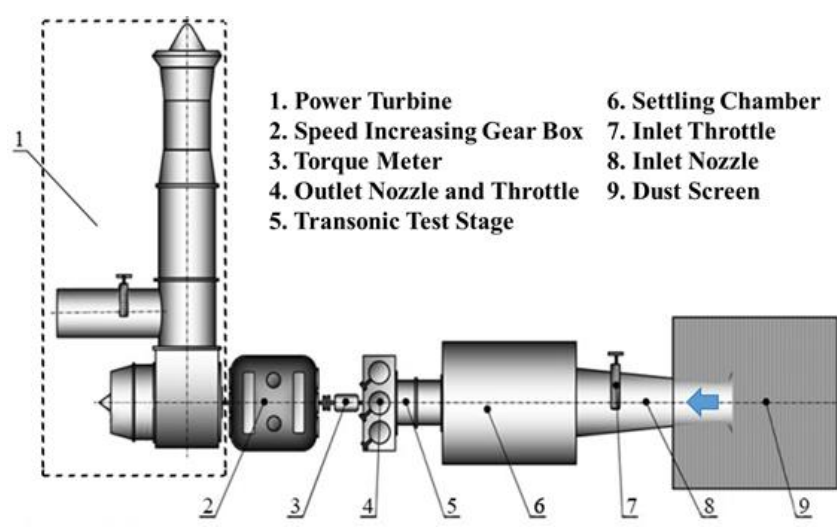

Figure1 Schematic Diagram of the Rig Test Facility

The test compressor is a transonic compressor stage which is actually used in an aero-engine, and the design parameters are shown in Table 1. A tandem stator design is employed in this compressor because of the high diffusion factor in the rotor hub region.
Table 1 Design Parameters of the Test Compressor

\begin{tabular}{ll}
\hline Parameter & Value \\
\hline Design Rotating Speed & $22000 \mathrm{rpm}$ \\
Design Total Pressure Ratio & 1.6 \\
Design Efficiency & 0.84 \\
Design Mass Flow Rate & $13.5 \mathrm{~kg} / \mathrm{s}$ \\
Number of Rotor Blades & 17 \\
Number of Each Row Stator Blades & 29 \\
Hub/Tip Ratio of Rotor & 0.565 \\
Aspect Ratio of Rotor & 0.956 \\
\hline
\end{tabular}

The casing treatment used in this experiment has the configuration of a kind of arc-shaped slot, which has been proved through tests to have excellent ability to improve the stall margin and minimize the peak efficiency loss of the compressor. Figure 2 shows the schematic diagram and the geometry of the casing treatment. The angles of the slots turn gradually from the axial direction to the direction along the blade passage, in order to minimize the loss of air flow coming in and out of the casing treatment. Besides, some detailed design parameters of the casing treatment are shown in Table 2.

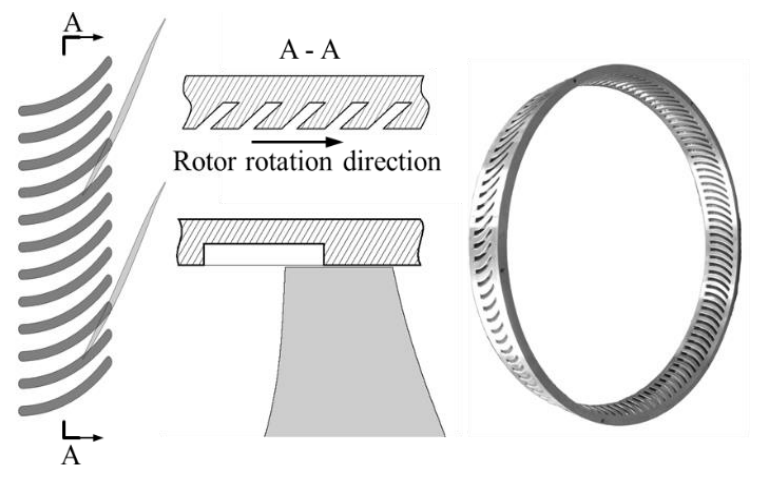

Figure 2 Schematic Diagram of the Arc-Shaped Casing Treatment

Table 2 Design Parameters of the Casing Treatment

\begin{tabular}{ll}
\hline Parameter & Value \\
\hline Open Area Ratio & $50 \%$ \\
Slot Number & 108 \\
Slot Depth & $7 \mathrm{~mm}$ \\
Overlap & $35 \%$ \\
Radial Skew Angle & $45^{\circ}$ \\
\hline
\end{tabular}

\section{Experimental Method}

Measurement setup. The axial and circumferential layout of the measurement points is shown in Figure 3. At sections $\mathrm{A}$ and $\mathrm{D}$, low-frequency total pressure combs are mounted to measure the total pressure at the inlet and outlet of the compressor. Because the inlet airflow is nearly uniform, one comb is sufficient for section A. However, at section $\mathrm{D}$, the flow field is non-uniform owing to the existence of blade wake, so 6 combs are arranged in this section, 3 in the mainstream area and 3 in the wake area, to obtain the exit total pressure more accurately. The radial 
measurement positions in a total pressure comb are presented in Figure 4. Because the areas between two adjacent positions are the same, the area-averaged total pressure of the section can be obtained by calculating the mean value of the 5 total pressure signals collected by the comb.

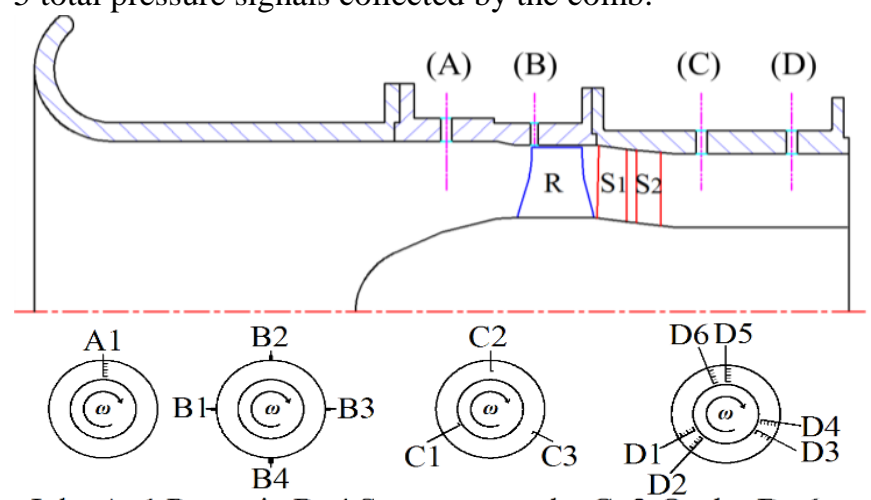

Inlet $\mathrm{A} \times 1$ Rotor tip $\mathrm{B} \times 4$ Stator root outlet $\mathrm{C} \times 2$ Outlet $\mathrm{D} \times 6$

Figure 3 Layout of the Measurement Points

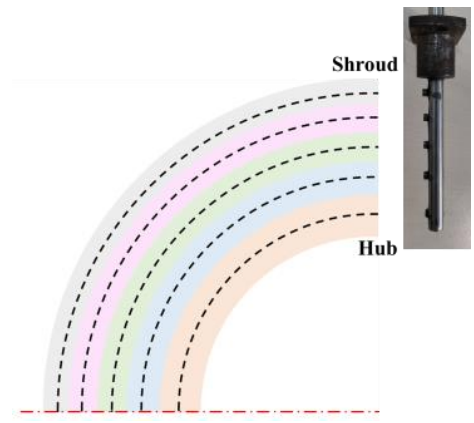

Figure 4 Schematic diagram of the radial measurement positions in a total pressure comb

At sections $\mathrm{B}$ and $\mathrm{C}$, high-frequency dynamic pressure sensors are deployed to detect the pressure disturbance signal and its propagation process. Section B is located near the leading edge of the rotor blade tip, and Four 15-psi static pressure probes (B1-B4) are flush mounted to the casing wall in this section to capture the generation and development of rotating stall cells in the rotor tip region. Section $C$ is set at the stator outlet. In this section, three dynamic total pressure probes $(\mathrm{C} 1-\mathrm{C} 3)$ are mounted, corresponding to the radial locations of $10 \%, 50 \%$ and $90 \%$ of blade span, in order to detect the disturbances at different radial positions.

It should be mentioned that for the tests when the casing treatment is installed, the dynamic pressure probes at section B cannot be mounted because of the skewed slots. Analysis of the disturbance signal in the tip region is mainly based on the data collected by probe $\mathrm{C} 3$, and these data are sufficient to support the conclusions.

In addition to the above measurement data, some parameters such as the rotational speed, flow rate, temperature, and ambient pressure are also measured. These steady data, together with the area-averaged total pressure obtained from section $\mathrm{A}$ and $\mathrm{D}$, will be used to identify the working condition and calculate the performance curves of the compressor.

Experimental procedure. The experiments are conducted at $65 \%$ of the design rotor speed when Mach number at the rotor tip is about 0.78 , so shock wave is absent. During the experiments, the compressor approaches to the instability boundary with the closing of the throttle valve, and several stable points are obtained during the throttling process. For the solid wall case without casing treatment, the throttle valve is fixed at the stall point (which is measured beforehand), and then the compressor will enter the instability state spontaneously. On the other hand, in the case with casing treatment, the compressor will be slowly throttled to the final instability from the peak efficiency point. The experiment is repeated several times to ensure that the results are reliable.

\section{EXPERIMENTAL RESULTS}

\section{Compressor Performance}

The compressor performance curves at $65 \%$ of the design rotor speed are plotted in Figure 5, including solid wall (SW) case and casing treatment (CT) case. The vertical axes in Figure 5(a) and Figure 5(b) are the total pressure ratio and efficiency, respectively, and the horizontal axes are the measured mass flow rate normalized by the design mass flow rate. As can be seen from this figure, the stall margin improvement (SMI) due to casing treatment is approximately $37 \%$, which is calculated by the following expression

$$
\mathrm{SMI}=\left(\frac{\left(m_{\mathrm{S}}\right)_{\mathrm{SW}}-\left(m_{\mathrm{S}}\right)_{\mathrm{CT}}}{\left(m_{\mathrm{S}}\right)_{\mathrm{SW}}}\right) \times 100 \%
$$

in which $m_{\mathrm{s}}$ is the mass flow rate at the stall point.

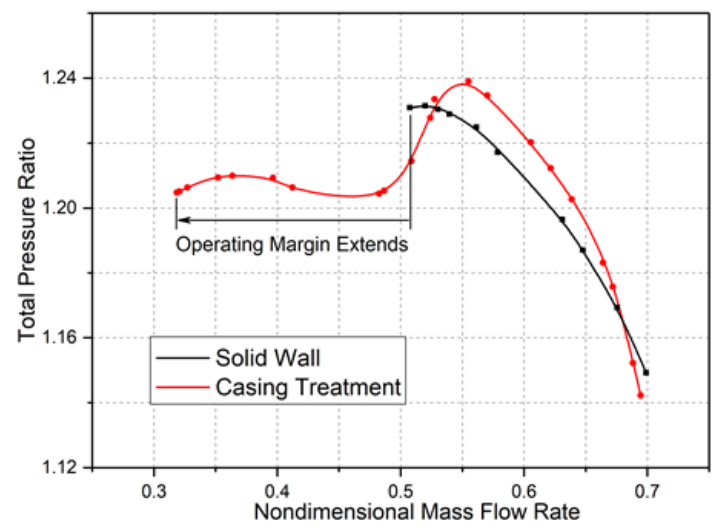

(a) Total Pressure Ratio

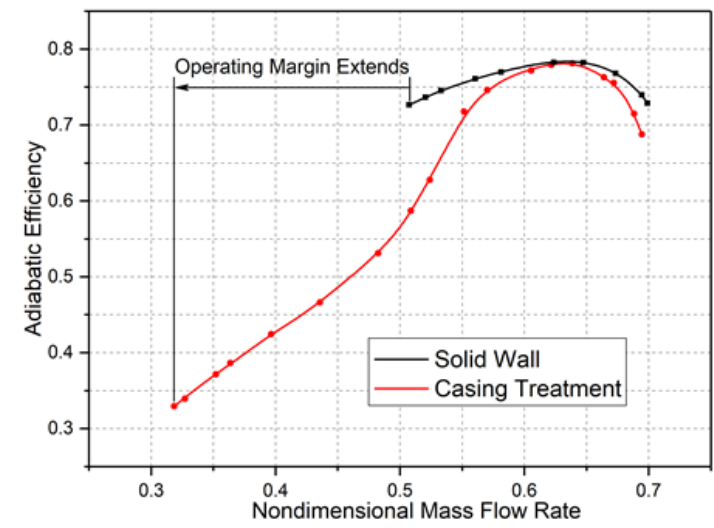

(b) Adiabatic Efficiency

Figure 5 Compressor Performance Before and After Casing Treatment 
Compared with the SW case, the growth rate of the total pressure ratio in $\mathrm{CT}$ case increases slightly before the nondimensional mass flow rate is throttled to 0.55 , resulting in a $0.6 \%$ increase in the maximum total pressure ratio. Then the total pressure drops significantly under CT case. However, the compressor will not lose its stability in this process, but continue to work after the mass flow rate decreases to 0.48 and the corresponding total pressure ratio drops to about 1.25. Since then, the total pressure ratio of the compressor will maintain at a relatively stable level, and the nondimensional mass flow rate can be further throttled to 0.32 .

For the efficiency characteristics, the adiabatic efficiency of the compressor is generally low at $65 \%$ design rotor speed in both cases. The peak efficiency and the corresponding mass flow rate are roughly unchanged after the casing treatment is installed. However, the efficiency decreases faster on both sides of the peak efficiency point in CT case, causing an efficiency penalty at other flow rates.

\section{Instability Evolution}

In order to study the influence of casing treatment on the instability inception, the initial instability disturbance and its evolution process in both cases with/without casing treatment are comparatively studied.

\section{Solid wall case}

In SW case, the nondimensional mass flow rate at the stall point is about 0.51 . The dynamic pressure signals are collected continuously after the throttle valve is fixed.

The data is first processed by the windowed Fourier transform (WFT), in order to obtain an overall understanding of the development of disturbances at different frequencies. Figure 6 shows the results of data processing. The time when the throttle valve is fixed is defined as the 0th revolution, and the dominant frequencies are marked. Figure 6(a) shows the static pressure data in the rotor tip region (collected by probe B1 in Figure 3). There are two dominant frequencies in this figure: the rotor rotation frequency (RRF, $239 \mathrm{~Hz}$ ), and the frequency of rotating stall cells, which is about $57 \%$ of the RRF $(136 \mathrm{~Hz})$. Figure $6(\mathrm{~b})$ is the total pressure data in the hub region of stator outlet (collected by probe $\mathrm{C} 1$ in Figure 3), and only the frequency of rotating stall cells can be seen in this figure.

These two dynamic pressure signals are filtered by a $500 \mathrm{~Hz}$ low-pass filter, and the processed time-domain signals are shown in Figure 7. As can be seen in this figure, the amplitude of pressure fluctuations in the tip region is small, until the sudden occurrence of stall disturbance at about the 1430th revolution. The signal from the hub is basically the same, while there are some low-frequency pressure oscillations before stall, which may be resulted from corner separation in the hub region [22], but have no direct contributions to the final stall in this case. To further study the instability inception, the dynamic signals on the rotor blade tip (B1-B4) are filtered by a $2000 \mathrm{~Hz}$ low-pass filter to remove the blade passing frequency, and the circumferential propagation of the disturbance is revealed in Figure 8. In this figure, the gray lines are the original signals and the red lines are the filtered results. It can be seen that there is a smallscale disturbance propagating at $66 \%$ rotation speed at the beginning, and then the velocity of circumferential propagation goes down to $57 \%$ as the disturbance develops into a large-scale stall cell, corresponding to the frequency of $136 \mathrm{~Hz}$. The results suggest that the type of stall inception is spike in SW case.

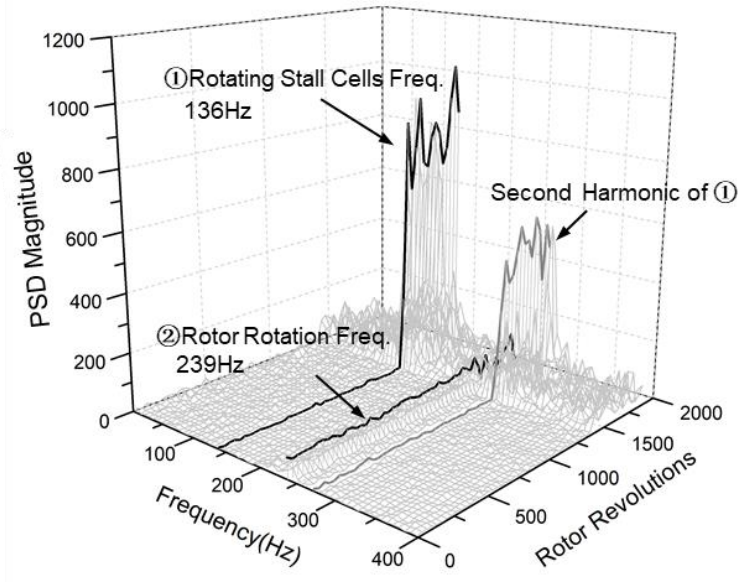

(a) Tip

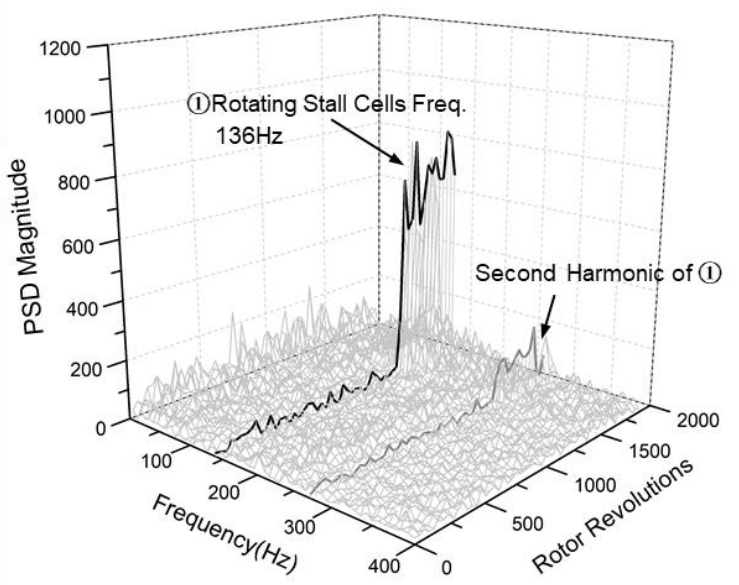

b) Hub

\section{Figure 6 WFT Results of the Dynamic Pressure at Rotor Tip and Stator Outlet Hub in SW Case}

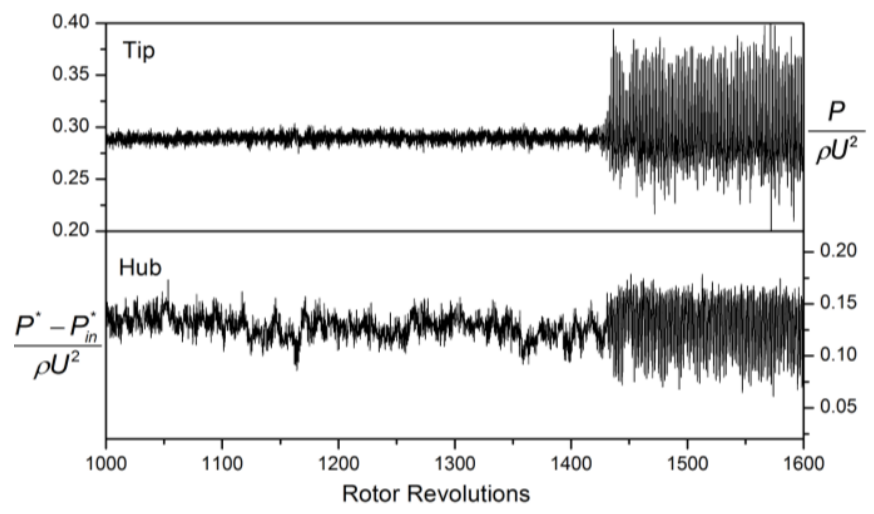

Figure 7 Time History of the Dynamic Pressure Signals at Tip and Hub in SW Case 


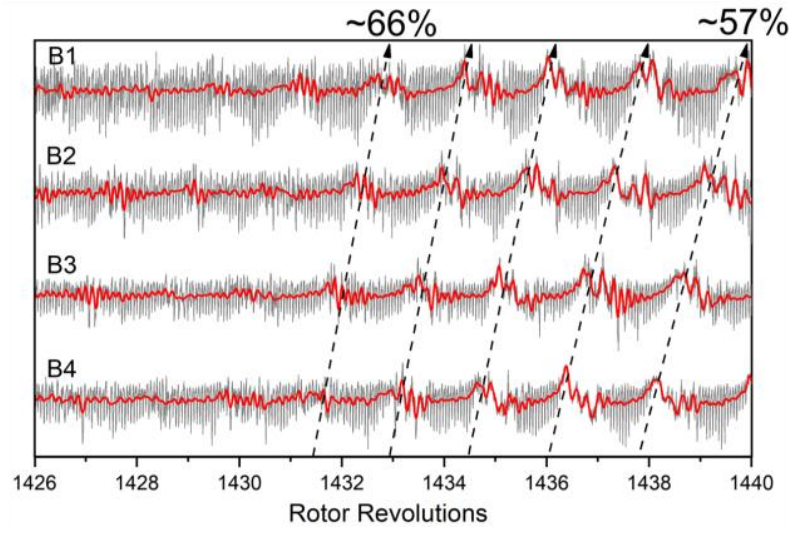

Figure 8 Circumferential Propagation of the Instability Inception in SW Case

\section{Casing treatment case}

As shown in Figure 5(a), for CT case, the compressor experiences a sharp drop in the total pressure ratio when throttled to the nondimensional mass flow rate at about 0.55 , which is larger than the stall point in SW case (about 0.51). The reason for this sharp drop can be explained in Figure 9. This graph shows the change of total pressure ratio at the tip and hub in the throttling process, obtained from the measurement data at different radial positions in section A and section D. As can be seen from this figure, the pressure ratio in the hub region experiences a sudden drop, while the pressure ratio in the tip region still maintains a relatively stable growth trend. This indicates that hub stall has occurred, but the tip can still work, so that the compressor did not lose its stability completely until the flow rate drops to about 0.32 .

In the experiment, owing to the long duration of the whole throttling process and based on the experience gained from repeated experiments, the dynamic data are collected continuously during two unstable phases - the hub stall phase and the final instability phase, which are marked as (1) and (2) in Figure 9, respectively. Next, the dynamic signals of these two phases are analyzed.

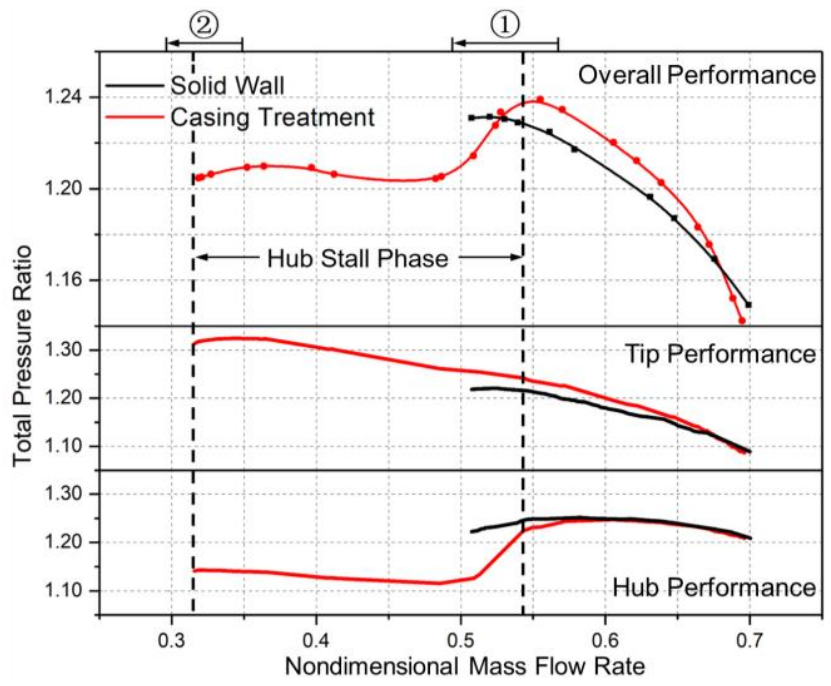

Figure 9 Total Pressure Ratio at Tip and Hub
(1) The occurrence of hub stall. The dynamic signals are also processed by the WFT first and the results are shown in Figure 10. The time when the continuous collection starts is defined as the 0th revolution.

As can be seen from Figure 10(b), a low-frequency disturbance with large amplitude suddenly appears in the hub region at about the 1500th revolution, but then disappears very soon. The low-frequency disturbance also occurs in the tip region (Figure 10(a)), but its amplitude is much smaller.

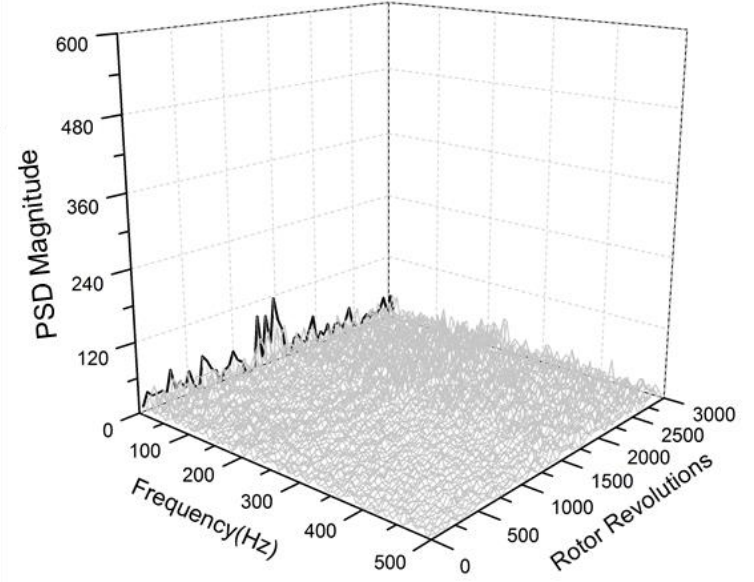

(a) Tip

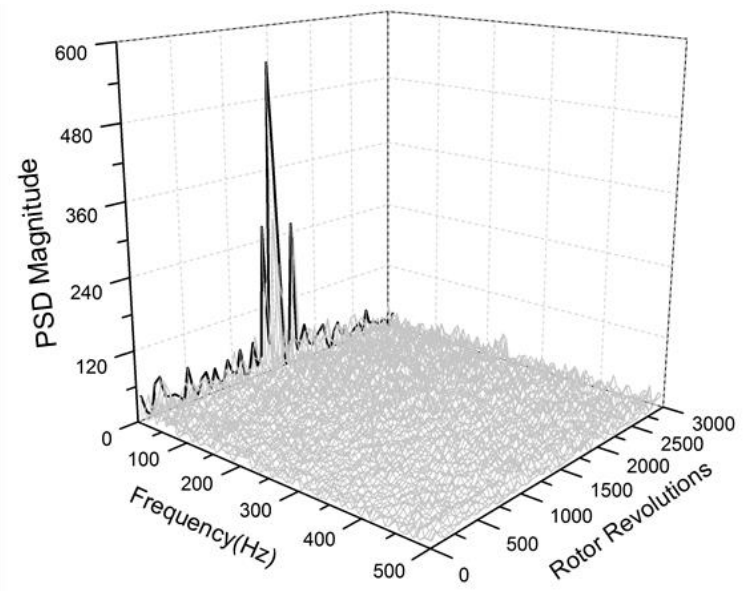

(b) Hub

\section{Figure 10 WFT Results of the Dynamic Pressure at Stator Outlet Tip/Hub in CT Case When Hub Stall Occurs}

Figure 11 shows the filtered time-domain signals, and the signal (enclosed by the red box) containing the lowfrequency disturbance is zoomed in. The magnitude of pressure fluctuation is small at all radial positions at the beginning. However, after the low-frequency disturbance occurs, the average total pressure in the hub region suddenly drops at about the 1530th revolution, and the pressure fluctuation increases significantly in the middle of the blade. In the tip region, however, the fluctuation increases slightly and the averaged total pressure remains roughly unchanged. 


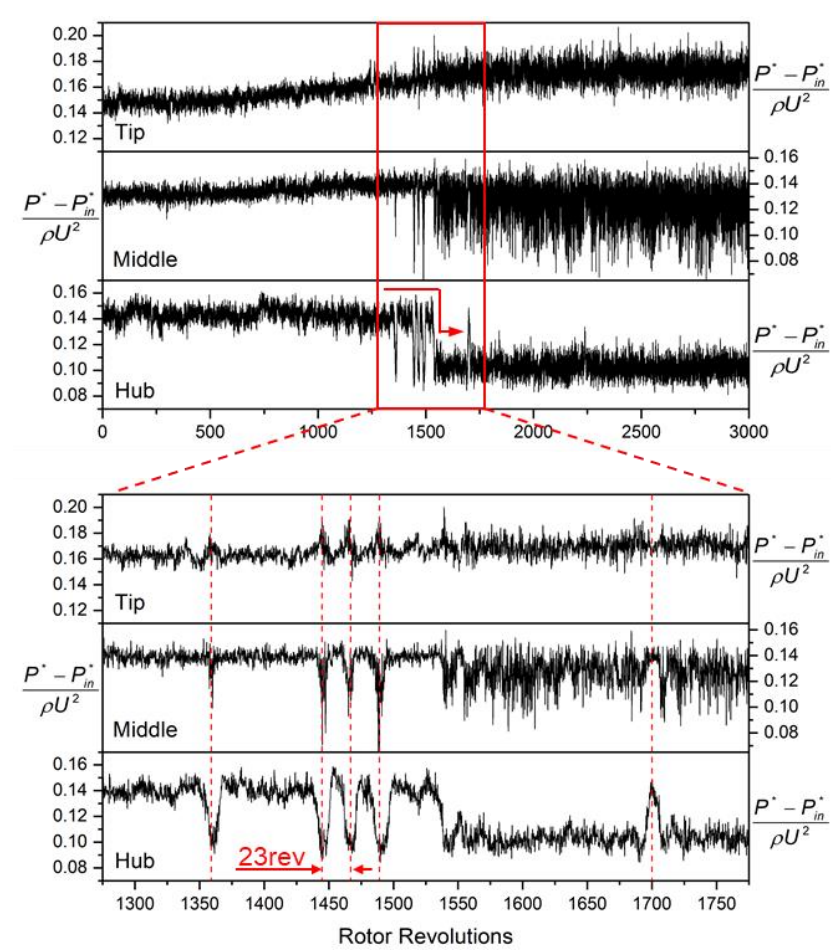

Figure 11 Time History of the Dynamic Pressure Signals at Stator Outlet Tip, Middle and Hub in CT Case When Hub Stall Occurs

The detailed characteristics of the low-frequency disturbance can be observed in the enlarged plots. The first pulse occurs simultaneously at different radial positions when it is about the 1360th revolution. In the hub region, the disturbance appears as a sudden drop of total pressure with the maximum magnitude. However, in the tip region, the amplitude of disturbance is much smaller and its phase is opposite to those in the middle and hub. Because the disturbance can be detected at the same time by the three probes located at different circumferential positions, the disturbance is considered to be axisymmetric to a certain extent. After the first disturbance has disappeared for dozens of revolutions, it occurs again at about the 1430th revolution and continues to oscillate for 3 times. According to the time scale of the disturbance ( 23 revolutions) and the FFT result in Figure 12, it can be determined that the frequency of the disturbance is very low, about $10 \mathrm{~Hz}$.

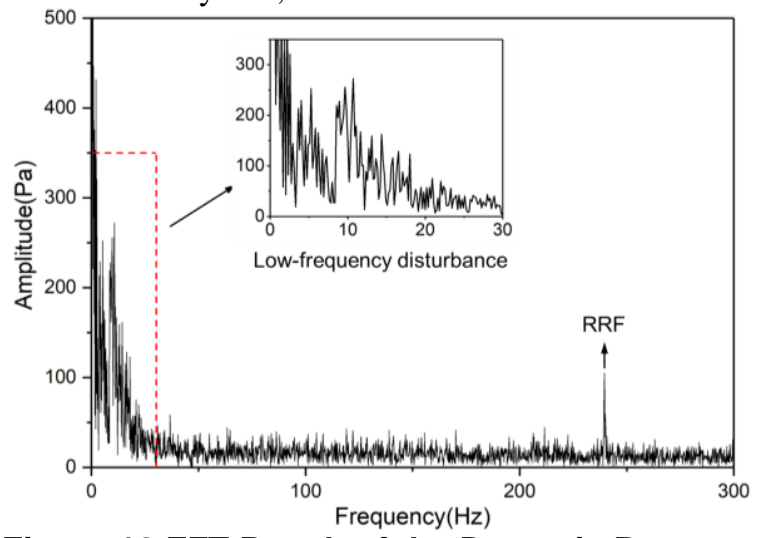

Figure 12 FFT Result of the Dynamic Pressure signal at Stator Outlet Hub in CT Case When Hub Stall occurs
Now the characteristics of this disturbance can be summarized as follow: (1) low-frequency; (2) axisymmetric; (3) occurring at the hub and causing an antiphase disturbance in the tip region. These characteristics are consistent with the partial-surge type of instability inception according to Reference [9].

In this experiment, however, since the presence of casing treatment suppresses the occurrence of rotating stall in the tip region, it is not possible for the partial-surge like disturbances to lead to rotating stall cells, which was verified in Reference [21]. Hence the disturbances only result in a part span stall in the hub region. After the occurrence of hub stall, the last low-frequency disturbance occurs at the 1700th revolution. However, the phase of this disturbance is opposite to that of the previous ones, suggesting a sudden recovery of the flow status in the hub region. After that, this low-frequency disturbance does not occur anymore, and the compressor keeps working in a relatively stable state.

(2) The final instability. The compressor loses its stability completely when the nondimensional mass flow rate is throttled to about 0.32 . The WFT results of dynamic total pressure signals are shown in Figure 13. It can be seen that the amplitude is small at all frequencies until a lowfrequency disturbance with large amplitude suddenly occurs at about the 2300 th revolution.

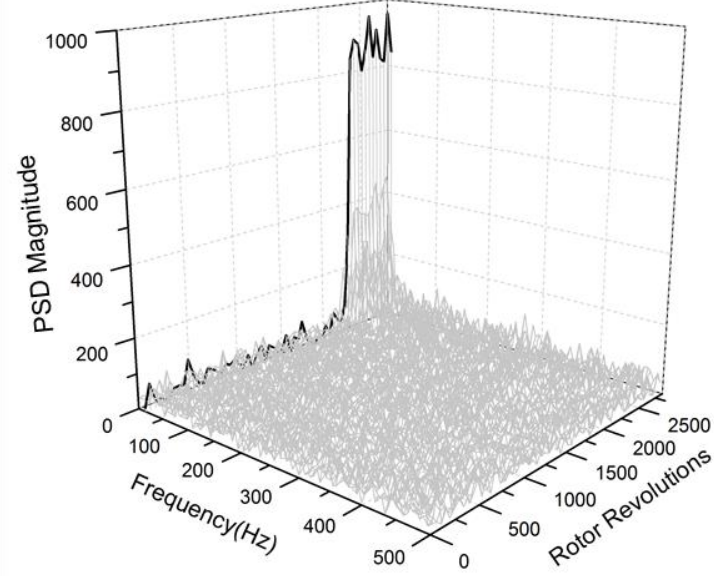

(a) Tip

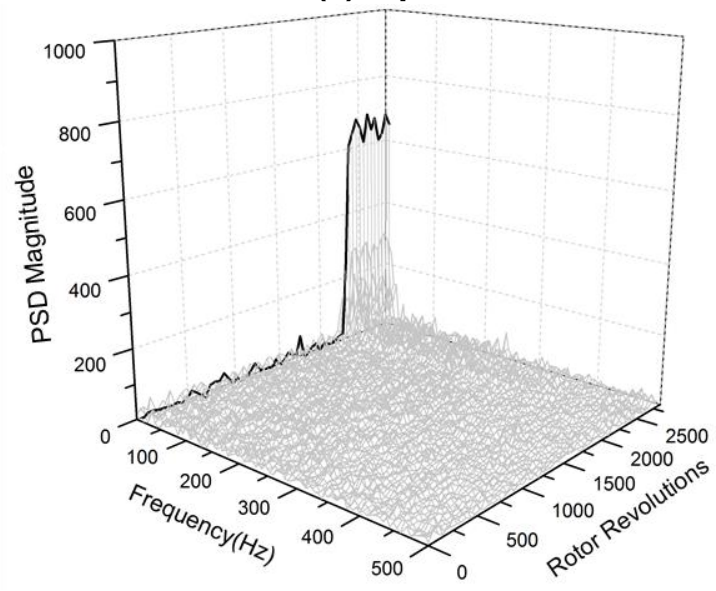

(b) Hub

Figure 13 WFT Results of the Dynamic Pressure at Stator Outlet Tip/Hub in CT Case When Final Instability Occurs 
For this low-frequency disturbance, more information is needed to prove whether it is same with the disturbance during hub stall. The dynamic pressure signals in this phase and the FFT result are given in Figure 14 and Figure 15. It can be found that there are some differences between these two kinds of low-frequency disturbances: (1) The frequency of this disturbance is about $16.5 \mathrm{~Hz}$, a little higher than that of the previous disturbance (about $10 \mathrm{~Hz}$ ); (2) The amplitude and phase of this disturbance are almost the same at all radial positions, different from the previous disturbance that occurs at the hub.

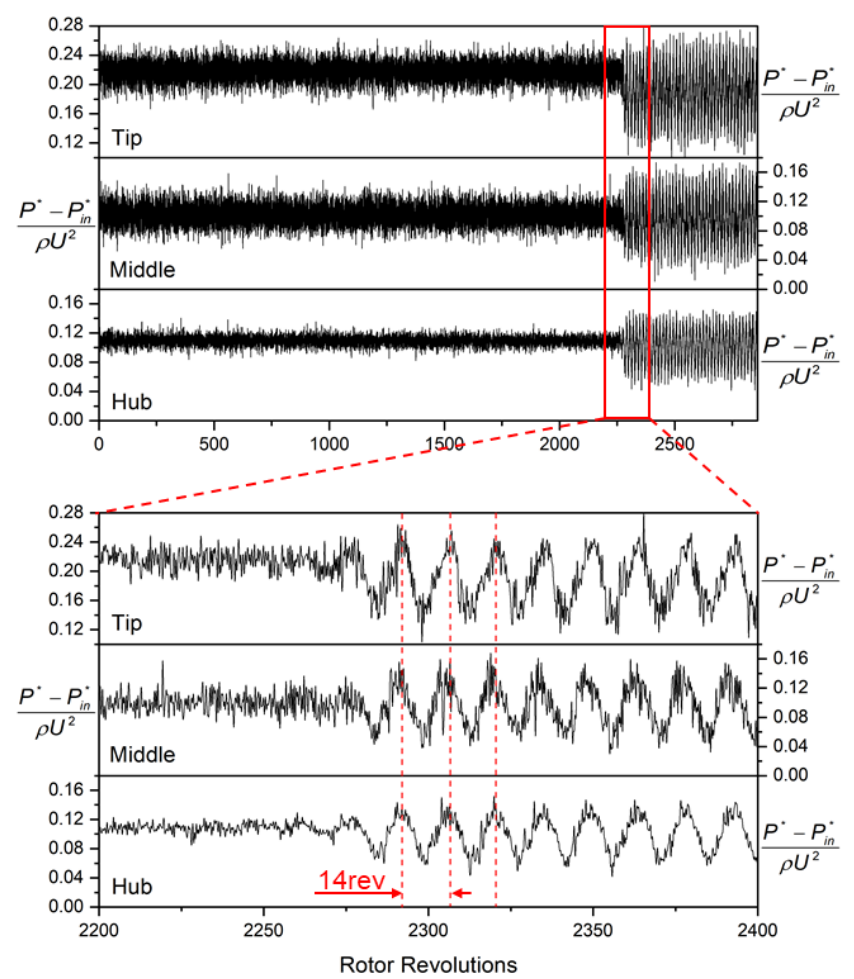

Figure 14 Time History of the Dynamic Pressure Signals at Stator Outlet Tip, Middle and Hub in CT Case When Final Instability Occurs

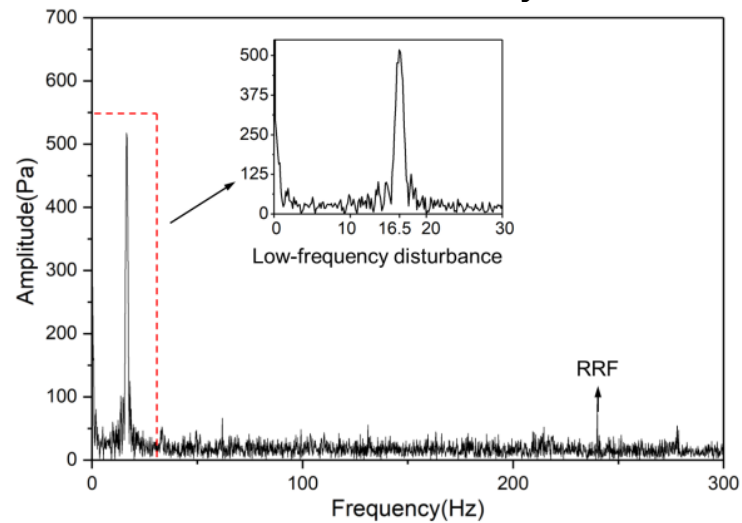

Figure 15 FFT Result of the Dynamic Pressure Signal at Stator Outlet Hub in CT Case When Final Instability Occurs

Considering the characteristics of this disturbance and the fact that the total pressure ratio can be detected to drop rapidly at this time, it can be concluded that this disturbance is caused by surge, which is the oscillation of the whole compression system. But since the rotor speed and the mass flow rate are quite low at this time, the intensity of the oscillation is relatively weak, so it behaves as a mild surge.

In summary, after the casing treatment is installed, the instability inception changes: spike no longer appears, but a low-frequency disturbance like partial surge occurs. While this low-frequency disturbance will not cause the rotating stall cells at rotor tip due to the existence of casing treatment, but only result in the local instability in the hub region. Finally, the compressor loses its stability in the form of mild surge.

\section{DISCUSSIONS}

For different types of instability inceptions, there have been some works focused on their transformation. Camp and Day [23] realized the switch between spike and modal wave by adjusting the inlet guide vane. Spakovszky et al. [24] also realized this switch by using jet-injectors and radial distortion screen. In addition, our previous studies [25] achieved the transformation between spike and partial surge by using radial distortion screen, and also concluded that the type of instability inception is related to the radial loading distribution: a highly loaded hub could very likely cause the occurrence of partial surge. Then, as for the study in this paper, can it be concluded that partial surge occurs because the casing treatment increases the hub loading at $65 \%$ design rotor speed?

In order to solve this problem, further numerical study was carried out to figure out how the blade loading changes after the casing treatment is installed. Since the variation of the radial loading distribution is an overall impact of the casing treatment, single-passage steady simulation is sufficient here. The CFX solver of ANSYS is used for calculation, and the SST k-omega turbulence model is adopted to close the discrete equations. The total grid number is about 1.03 million, including the main flow region $(0.67$ million) and casing treatment domain ( 0.36 million). The calculated performance and spanwise distributions of total pressure compared with the experimental results are shown in Figure 16 and 17. It can be seen that the numerical results agree well with the experimental results. Since only a qualitative analysis of the loading distribution is needed in this paper, these results are accurate enough for the subsequent analysis.

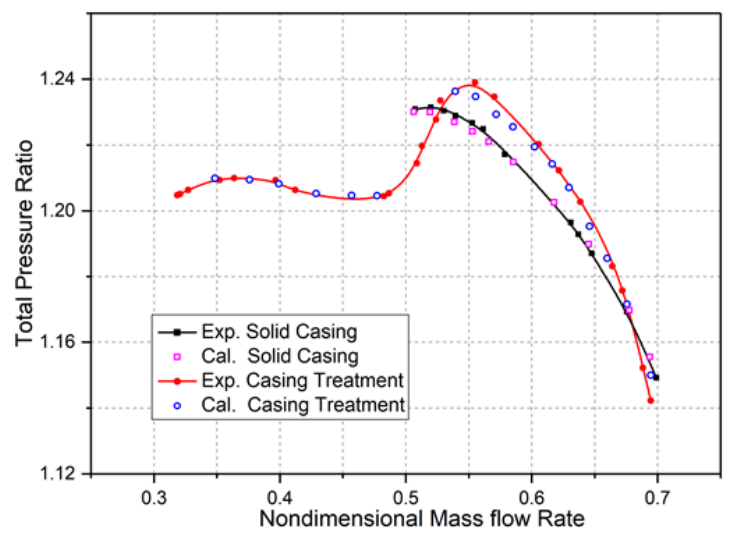

Figure 16 Comparison of compressor performance between experimental and numerical results 


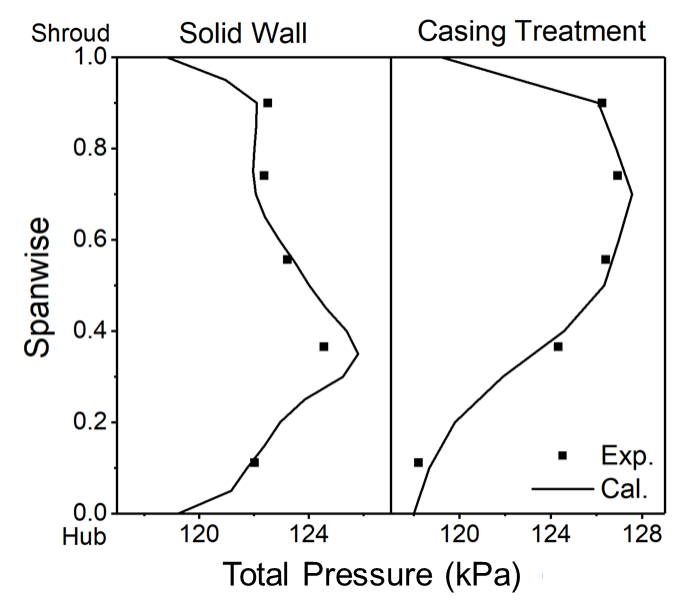

Figure 17 Spanwise distributions of total pressure near the stall point of solid wall case

The blade loading distribution (denoted by the diffusion factor) obtained from numerical results are shown in Figure 18. For both rotor and stator, the blade loading distributions near the choke point are almost the same between SW and CT cases, except that the rotor tip loading of CT case is a little higher than that of SW case. This is because the flow out from the skewed slot increases the attack angle at the rotor tip. While when the mass flow corresponding to the stall point of solid wall case is reached, the presence of casing treatment has a great influence on the distributions of diffusion factor. For the rotor, the loading increases obviously except the tip region after casing treatment. For the stator, the loading also increases a lot under around 30\% span. This result confirms the foregoing speculation that the casing treatment will change the radial loading distribution, increase the blade loading in the hub region and then lead to the partial surge-type disturbance.

Based on the calculation result, the reason why casing treatment can change the loading distribution can be explained as follow. Because of the casing treatment, the flow in the tip region is improved and more fluid will flow through the middle and tip area at a given total flow rate. Therefore, the corresponding decrease of flow rate in the hub region will increase the hub loading, aggravating the corner separation in the hub region and resulting in the occurrence of partial surge.

It should be noted that the compressor studied in this paper does have some limitations. The most important one is that its hub loading is relatively high, so partial surge is easy to occur even in solid wall case. However, it may not be common that the hub loading is relatively high for other single-stage compressors, so the effect of casing treatment in this paper is not easy to happen. But for the multi-stage compressor, a similar situation may occur after matching between stages, so it is still meaningful to study the influence of casing treatment on the radial loading distribution. Besides, for this study, the conclusion that the stall margin is improved is drawn based on the assumption that the hub stall is acceptable for this compressor. While if similar behavior occurs in an actual aero-engine, this kind of sudden part-span stall is very likely to be unacceptable, which means that the casing treatment fails to extend the operating margin and even results in the earlier occurrence of part-span stall. In this case, however, it is more important to pay attention to the change of radial loading distribution, in order to avoid the failure of casing treatment.

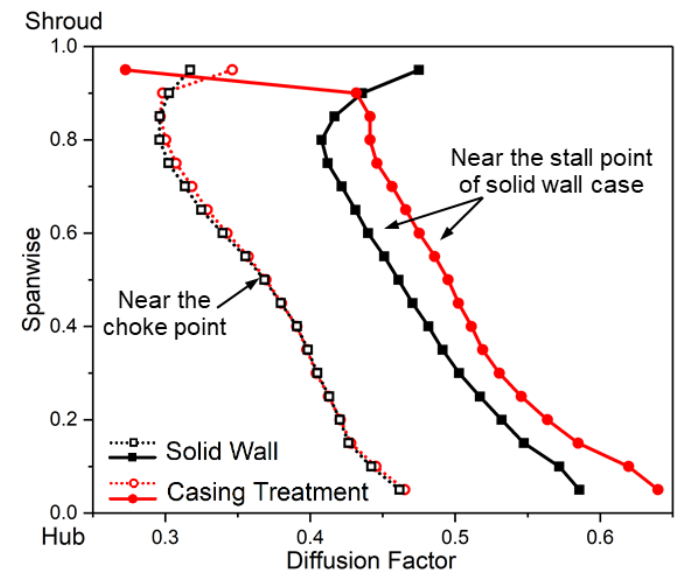

(a) Rotor

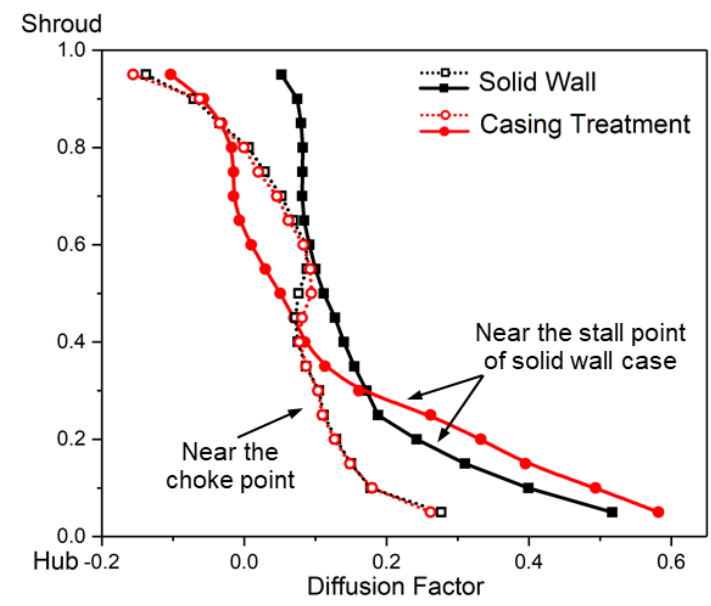

(b) Stator

\section{Figure 18 Radial Distributions of Diffusion Factor With/Without Casing Treatment}

\section{CONCLUSIONS}

The switch between two types of instability inceptions in solid wall/ casing treatment cases at the $65 \%$ of the design rotating speed is studied in this paper, and the main conclusions are as follows:

(1) At the $65 \%$ of the design rotating speed, the installation of the casing treatment improves the stall margin by $37 \%$ while the maximum efficiency is basically the same.

(2) In the solid wall case without casing treatment, the instability inception is spike. After the casing treatment is installed, spike no longer appears, but a disturbance similar to partial surge occurs. This disturbance causes part-span instability in the hub region, but the whole compressor can still operate. Finally, the compressor loses its stability in the form of mild surge.

(3) The casing treatment can alter the radial distribution of blade loading and increase the blade hub loading, which is the reason why the instability inception changes from spike to partial surge. 


\section{NOMENCLATURE}

$\begin{array}{ll}\text { CT } & \text { casing treatment } \\ \text { SW } & \text { solid wall } \\ \text { SMI } & \text { stall margin improvement } \\ P & \text { static pressure } \\ P^{*} & \text { total pressure } \\ P_{i n}^{*} & \text { total pressure at the inlet } \\ \rho & \text { fluid density } \\ U & \text { tip velocity in circumferential direction } \\ \left(m_{\mathrm{S}}\right)_{\mathrm{SW}} & \text { mass flow at stall point in solid wall case } \\ \left(m_{\mathrm{S}}\right)_{\mathrm{CT}} & \text { mass flow at stall point in casing treatment case }\end{array}$

\section{ACKNOWLEDGMENTS}

The authors acknowledge the support of National Natural Science Foundation of China (Nos. 51636001 and 51706008), National Science and Technology Major Project (2017-II-0005-0018), and Aeronautics Power Foundation of China (No.6141B090315).

\section{REFERENCES}

[1] Moore, F. K. and Greitzer, E. M., (1986), A Theory of Post-Stall Transients in Axial Compression Systems: Part1Part2, ASME Journal of Engineering for Gas Turbines and Power, 108(1), pp 68-76, 108(2), pp. 231-239.

[2] Hynes, T. P. and Greitzer, E. M., (1987), A Method for Assessing Effects of Circumferential Flow Distortion on Compressor Stability, ASME Journal of Turbomachinery, 109(3), pp. 371-379.

[3] Epstein, A. H., Ffowcs Williams, J. E. and Greitzer, E. M., (1989). Active Suppression of Aerodynamic Instabilities in Turbomachines. AIAA Journal of Propulsion and Power, 5(2), pp. 204-211.

[4] McDougall, N. M., Cumpsty, N. A. and Hynes, T. P., (1990). Stall Inception in Axial Compressors, ASME Journal of Turbomachinery, V112(1), pp. 116-123.

[5] Day, I. J., (1993), Stall Inception in Axial Flow Compressors, ASME Journal of Turbomachinery, V115(1), pp. 1-9.

[6] Jackson, A. D., (1987), Stall Cell Development in an Axial Compressor, ASME Journal of Turbomachinery, V109(4), pp. 492-498.

[7] Inoue, M., Kuroumaru, M., Iwamoto, T. and Ando, Y., (1991), Detection of a Rotating Stall Precursor in Isolated Axial Flow Compressor Rotors, ASME Journal of Turbomachinery, 113(2), pp. 281-287.

[8] Dodds, J. and Vahdati, M., (2015), Rotating Stall Observations in a High Speed Compressor-Part I-Part II ASME Journal of Turbomachinery, 137(5), pp. 051002051003.

[9] Li, Q., Pan, T., Li, Z., Sun, T. and Gong, Y., (2014), Experimental Study of Compressor Instability Inception in a Transonic Axial Flow Compressor, ASME Paper No. GT2014-25190.

[10] Li, Q., Pan, T., Sun, T., Li, Z. and Gong, Y., (2015), Experimental Investigations on Instability Evolution in a Transonic Compressor at Different Rotor Speeds, Proceedings of the Institution of Mechanical Engineers, Part
C: Journal of Mechanical Engineering Science, 229(18), pp. 3378-3391.

[11] Takata, H., Tsukuda, Y., (1977), Stall Margin Improvement by Casing Treatment-Its Mechanism and Effectiveness, Journal of Engineering for Power, 99(1), pp. 121-133.

[12] Fujita, H. and Takata, H., (1984), A Study of Configurations of Casing Treatment for Axial Flow Compressors, Bulletin of JSME, 27(230), pp. 1675-1681.

[13] Prince, D. C., Wisler, D. C. and Hilvers, D. E., (1974), Study of Casing Treatment Stall Margin Improvement Phenomena, Report No. NASA CR-134552.

[14] Alone, D. B., Kumar, S. S., Thimmaiah, S. M., et al., (2014), Improvement of Moderately Loaded Transonic Axial Compressor Performance Using Low Porosity Bend Skewed Casing Treatment, International Journal of Rotating Machinery, 2014.

[15] Tuo, W., Lu, Y., Yuan, W., Zhou, S. and Li, Q., (2011), Experimental Investigation on the Effects of Unsteady Excitation Frequency of Casing Treatment on Transonic Compressor Performance, Journal of Turbomachinery, 133(2), pp. 021014.

[16] Hathaway, M. D., (2002), Self-recirculating Casing Treatment Concept for Enhanced Compressor Performance, ASME Paper No. GT2002-30368.

[17] Sun, X., Sun, D., Liu, X., et al., (2014), Theory of compressor stability enhancement using novel casing treatment, part I \& part II, Journal of Propulsion and Power, 30(5), pp. 1224-1247.

[18] Smith, G. D. J. and Cumpsty, N. A., (1984), Flow Phenomena in Compressor Casing Treatment, Journal of Engineering for Gas Turbines and Power, 106(3), pp. 532541.

[19] Wilke, I. and Kau, H. P., (2002), A Numerical Investigation of The Influence of Casing Treatments on the Tip Leakage Flow in a HPC Front Stage, ASME Paper No. GT 2002-30642.

[20] Emmrich, R., Honen, H. and Niehuis, R., (2007), Time Resolved Investigations of an Axial Compressor with Casing Treatment: Part 1 - Experiment, ASME Paper No. GT2007-27581.

[21] Pan, T., Li, Q., Yuan, W. and Lu, H., (2017), Effects of Axisymmetric Arc-Shaped Slot Casing Treatment on Partial Surge Initiated Instability in a Transonic Axial Flow Compressor, Aerospace Science and Technology, 69(2017), pp. 257-268.

[22] Hu, J., Li, Q., Pan, T. and Gong, Y., (2018), Numerical Investigations on Stator Hub Initiated Stall in a Single-Stage Transonic Axial Compressor, Aerospace Science and Technology, 80(2018), pp. 144-155.

[23] Camp, T. R. and Day, I. J., (1998), A Study of Spike and Modal Stall Phenomena in a Low Speed Axial Compressor, ASME Paper No. 97-GT-526.

[24] Spakovszky, Z. S., et al. (1999), Rotating Stall Control in a High-Speed Stage with Inlet Distortion: Part I-Radial Distortion, Journal of Turbomachinery 121(3), pp. 510-516.

[25] Pan, T., Li, Q., Li, Z. and Gong, Y., (2017), Effects of Radial Loading Distribution on Partial-Surge-Initiated Instability in a Transonic Axial Flow Compressor, ASME Journal of Turbomachinery, 139(10), pp. 101010. 